\title{
LOIS Ximena and Valentina VAPNARSKY (eds), Lexical categories and root classes in Amerindian languages, Peter Lang AG, Bern, 2006, vi + 389 p., réf. dissém.
}

\section{Bernard Pottier}

\section{CpenEdition}

\section{Journals}

Édition électronique

URL : https://journals.openedition.org/jsa/7283

DOI : $10.4000 /$ jsa.7283

ISSN : 1957-7842

Éditeur

Société des américanistes

Édition imprimée

Date de publication : 1 décembre 2007

ISSN : 0037-9174

Référence électronique

Bernard Pottier, « Lois Ximena and Valentina vapnarsky (eds), Lexical categories and root classes in Amerindian languages, Peter Lang AG, Bern, 2006, vi + 389 p., réf. dissém. », Journal de la Société des américanistes [En ligne], 93-1 | 2007, mis en ligne le 23 janvier 2008, consulté le 04 septembre 2022. URL : http://journals.openedition.org/jsa/7283 ; DOI : https://doi.org/10.4000/jsa.7283

Ce document a été généré automatiquement le 4 septembre 2022.

Tous droits réservés 


\section{LoIS Ximena and Valentina} VAPNARSKY (eds), Lexical categories and root classes in Amerindian languages, Peter Lang AG, Bern, 2006, vi + 389 p., réf. dissém.

\section{Bernard Pottier}

1 Les dix articles qui constituent ce volume reprennent des contributions présentées lors du 51e Congrès des Américanistes (Santiago de Chile, 2001), auxquelles se sont ajoutés d'autres articles autour du problème de la polyvalence des racines lexicales.

2 Les domaines linguistiques abordés sont variés: andin (mapuzungun, par Marisa Malvestitti) ; caribe (kuikuro, par Bruna Franchetto ; wayana, par Eliane Camargo) ; tupiguarani (par Francesc Queixalós); maya (tzeltal, par Aurore Monod Becquelin; yukatek et itza, par Ximena Lois et Valentina Vapnarsky et par Barbara Pfeiler); muskogean (choctaw, par Marcia Haag); iroquois (cherokee, par Marcia Haag), sioux (hocąk, par Johannes Helmbrecht).

Chaque article est dense, bien documenté, et s'adresse aux spécialistes. C'est pourquoi il est heureux que les deux éditrices aient rédigé une introduction de trente pages, dans laquelle elles exposent clairement la problématique.

La question centrale est la suivante : un radical est-il prédestiné à être syntaxiquement un « nom » ou un « verbe » (ou éventuellement un « adjectif ») ? À première vue, main et caillou ont une vocation de nom, dormir et penser sont par nature des verbes. Dans une langue comme le français, la dérivation assure le changement de classe syntaxique: manier, caillouter, la pensée, mais dormir n’a pas de dérivé immédiat (dormition est issu du latin). L'article de Richard Carter sur l'anglais (et le français), intitulé "Polycategoriality and predictability", donne une utile idée de la complexité des interprétations dans une langue indo-européenne. 
Dans de nombreuses langues du monde, et parmi elles plusieurs des langues amérindiennes analysées dans cet ouvrage, il semble y avoir au départ une grande indétermination, un peu comme fish ou walk en anglais. Le lexème nu peut théoriquement fonctionner dans des combinatoires qui l'orientent vers la classe nominale ou vers la classe verbale (a walk, I walk). Chaque langue a son propre comportement en tolérant ou exigeant la présence de certaines catégories comme l'aspect, le temps, la modalisation (l'ex-député, une possible réorganisation, il réfléchit longuement ou une longue réflexion), catégories qui peuvent être exprimées par une morphologie liée (comme "fais-able" ou latin "e-bibere"). Une question liée à celle de la nature première du radical est sa prédicabilité : peut-il être directement prédicatif en situation syntaxique prototypique, ou lui faut-il un élément de plus? Sur le plan diachronique, on peut penser que les radicaux sont omniprédicatifs (Launey et Queixalós) et ils se seraient progressivement spécialisés.

Un problème encore plus général est soulevé par ces riches contributions : celui des rapports entre le niveau conceptuel (le «lexique mental») et les signes linguistiques. Philosophes et linguistes généralistes en viennent régulièrement à opposer les " choses " (êtres, objets, lieux...) et les "événements » (actions, procès...), les premiers étant fortement stables, les seconds moins stables. Nous avons le sentiment que cela est largement conforme à l'intuition et fréquemment traduit dans le comportement basique des langues. L'adjectivation (nominale ou verbale) indiquerait des propriétés plus ou moins stables. À mon avis, on peut prendre cela comme un tertium comparationis et rechercher quels écarts présentent les langues par rapport à cette référence. Ajoutons qu'il ne nous semble pas opportun d'établir un lien direct entre le nom et la catégorie de l'espace, pas plus qu'entre le verbe et la catégorie du temps. Arbre est nécessairement dans l'espace, mais s'inscrit aussi dans la durée. Inversement, dormir évoque de la durée, mais renvoie évidemment à une entité dormante.

7 Toutes ces réflexions sont nées des exposés dont l'abondante documentation ne peut être détaillée ici, mais nous recommandons ce livre aux ethnolinguistes et aux anthropologues du monde amérindien dans son ensemble. Le lecteur qui voudrait une introduction en français pourrait se reporter à l'ouvrage de Jon Landaburu et Francesc Queixalós (éds), Faits de langues: Méso-Amérique, Caraïbes, Amazonie (vol.1 et 2, Ophrys, Paris, 2002, 262 p. et 2003, 246 p.), où quelques-uns des auteurs recensés ont collaboré.

\section{AUTEURS}

\section{BERNARD POTTIER}

Institut de France, Paris 